\title{
Sistem Informasi Penggajian Karyawan Pada PT. Malka Makarya Selaras Jakarta
}

\author{
Nanda Ainnoor Azidah ${ }^{1}$, Indah Ariyati 2,* \\ * Korespondensi: e-mail: indah.ayi@bsi.ac.id
}

\begin{abstract}
1 Sistem Informasi Akuntansi; Universitas Bina Sarana Informatika; Jl. Kramat Raya No.98, Kwitang Jakarta Pusat, 021-8000063; e-mail: nanda.azidah25@gmail.com

$\frac{2}{2}$ Sistem Informasi; Universitas Bina Sarana Informatika; Jl. Kramat Raya No.98, Kwitang Jakarta Pusat, 0218000063; e-mail: indah.ayi@bsi.ac.id

Submitted : 9 Agustus 2021

Revised : 13 September 2021

Accepted : 12 Oktober 2021

Published : 30 November 2021
\end{abstract}

\section{Abstract}

PT Malka Makarya Selaras Jakarta is a human resource management consulting services company. Problems in the salary calculation process such as making payslips and the absence of a company database are only paper document archives, over time there are often typos and lost files. Researchers build an employee payroll information system that is displayed on the company's internal website page where the manager is only a special payroll officer. The software development method in this research is the waterfall model. The results of the study obtained that the salary calculation process can be carried out on the employee payroll information system so as to produce faster and more accurate information, payroll can directly print salary slips as official evidence between the company and employees, payroll information systems as a benchmark for technological progress so as to facilitate the company's performance in decision-making.

Keywords: Information Systems, Payroll, Waterfall.

\section{Abstrak}

PT Malka Makarya Selaras Jakarta merupakan perusahaan jasa konsultasi manajemen sumber daya manusia. Masalah dalam proses perhitungan gaji seperti pembuatan slip gaji dan tidak adanya database perusahaan hanya berupa arsip dokumen kertas, seiring dengan waktu berjalan sering terjadi kesalahan ketik dan kehilangan arsip. Peneliti membangun sistem informasi penggajian karyawan yang ditampilkan dalam halaman website internal perusahaan dimana pengelolanya hanyalan petugas khusus penggajian. Metode pengembangan perangkat lunak pada penelitian ini adalah model air terjun (waterfall). Hasil penelitian diperoleh proses perhitungan gaji dapat dilakukan pada sistem informasi penggajian karyawan sehingga menghasilkan informasi yang lebih cepat dan akurat, penggajian dapat secara langsung mencetak slip gaji sebagai bukti resmi antara perusahaan dengan karyawan, sistem informasi penggajian sebagai tolak ukur kemajuan teknologi sehingga mempermudah kinerja perusahaan dalam pengambilan keputusan.

Kata kunci: Penggajian, Sistem Informasi, Waterfall. 


\section{Pendahuluan}

Perkembangan teknologi saat ini telah mendorong masyarakat memasuki era globalisasi informasi, salah satunya teknologi komputer yang diciptakan untuk mempermudah pekerjaan manusia (Hardi \& Leidiyana, 2020) berpengaruh besar dalam pengolahan data yang membutuhkan kecepatan dan ketelitian (Misriati, 2015). Perkembangan tersebut juga meningkatkan kualitas sumber daya manusia (Istiana \& Ariyati, 2017) yang dapat membangun sistem terkomputerisasi dalam berbagai bidang usaha untuk mempermudah perusahaan dalam pengambilan keputusan.

PT Malka Makarya Selaras merupakan salah satu perusahaan jasa konsultasi di daerah Jakarta yang berkaitan dengan manajemen sumber daya manusia. Bentuk kompensasi sebagai balas jasa yang diberikan perusahan atas kinerja karyawannya (Hidayatun, 2016), dimana petugas perusahaan bertugas mencatat dan memproses data-data yang digunakan untuk membayar gaji pegawai (Siswanto \& Alfiandanu, 2015) dan membuat laporan penggajian karyawan untuk diajukan kepada pimpinan perusahaan (Rahaningsih et al., 2019). Sistem penggajian pada PT Malka Makarya Selaras masih dilakukan secara manual sehingga sering mengalami masalah dalam proses perhitungan gaji, pembuatan slip gaji dan tidak adanya database perusahaan hanya berupa arsip dokumen kertas, seiring dengan waktu berjalan sering terjadi kesalahan ketik dan kehilangan arsip. (Mania et al., 2016). Berdasarkan permasalahan yang ada pada PT Malka Makarya Selaras, maka dibutuhkan sistem informasi penggajian yang dapat membantu mempercepat dalam pengelolaan data dan menghemat waktu serta terhindar dari kesalahan pemasukan data (Faizah et al., 2020) sistem informasi ini dapat berjalan dengan baik jika ditunjang dengan prosedur kerja dan sumber daya manusia (Ariyati, 2018) dalam perusahaan tersebut.

Peralatan pendukung sebagai model sistem dapat digambarkan menggunakan diagram dan simbol yang menunjukkan fungsinya masing - masing seperti Unified Modelling Language (Muslihudin \& Oktafianto, 2016), pada penelitian ini, peneliti menggunakan diagram use case diagram, activity diagram dan sequence diagram. Peneliti menggambarkan hubungan antar entitas melalui entity relation diagram.

Peneliti membangun sistem informasi penggajian karyawan yang ditampilkan dalam halaman website internal perusahaan dimana pengelolanya hanyalan petugas khusus penggajian. Halaman website ini berisi informasi penting dan rahasia berupa text, gambar, video audio dan cetakan dokumen lainnya yang semuanya tersimpan dalam database. Bahasa pemrograman yang digunakan adalah Java dengan aplikasi netbeans IDE 8.0.2

\section{Metode Penelitian}

Metode pengumpulan data yang digunakan dalam penelitian ini adalah (a) Metode Observasi, teknik pengumpulan data dengan metode observasi diperoleh dengan cara mengamati langsung objek penelitian untuk melihat, mempelajari dan memahami arus data dan prosedur sistem berjalan. Kegiatan observasi dilakukan oleh peneliti dengan mengamati 
langsung prosedur sistem berjalan yang ada di PT Malka Makarya Selaras Jakarta; (b) Metode Wawancara, Metode ini dilakukan dengan cara tanya jawab antara penelti dengan petugas PT Malka Makarya Selaras Jakarta untuk mendapatkan data dan informasi; (c) Metode Studi Pustaka, Metode ini dilakukan dengan membaca literatur-literatur yang berkaitan dengan penelitian ini.

Metode pengembangan perangkat lunak pada penelitian ini adalah model air terjun (waterfall). Model waterfall adalah model yang menyediakan pendekatan alur hidup perangkat lunak secara sekuensial atau turut dimulai dari analisis, desain, pengodean, penguji dan tahap pendukung (Sukamto \& Shalahuddin, 2015).

Tahap awal dengan melakukan analisis kebutuhan sistem, peneliti mempelajari dan memahami persoalan yang ada pada perangkat lunak, peneliti mengidentifikasi kebutuhan user dengan mengumpulkan informasi kedalam bentuk kebutuhan fungsional, antarmuka dan unjuk kerja sistem. Tahap kedua desain system, peneliti mendesain perangkat lunak yang akan dibangun dengan membuat entity relation diagram, usecase diagram, sequence diagram, yang mengacu pada data analisis kebutuhan perangat lunak. Tahap ketiga pembuatan kode program, peneliti membuat kode program kemudian diterjemahkan dalam perangkat lunak berdasarkan desain yang telah dibuat sebelumnya. Tahap keempat pengujian, peneliti melakukan pengujian perangkat lunak secara keseluruhan. pengujian dilakukkan melalui BlackBox Testing. Tahap terakhir Pendukung atau Pemeliharaan, peneliti melakukan backup data perangkat lunak, memperbaiki perangkat lunak saat terdeteksi kesalahan setelah pengujian.

\section{Hasil dan Pembahasan}

\subsection{Prosedur Sistem Berjalan}

Proses bisnis dibuat agar menjelaskan tahapan setiap proses dalam perusahaan. Proses perhitungan penggajian diawali karyawan absen menggunakan kartu absensi setiap hari dan jika lembur maka mengisi form lembur. Personalia akan merekap absensi dan form lembur secara periodik setiap bulan diserahkan ke manajer operasional.

Oleh manajer operasional menghitung gaji karyawan setiap periode bulan berjalan dan dibuatkan slip gaji serta debet note ke bagian keuangan, agar dilakukan pembayaran gaji. Slip gaji 2 rangkap ditandatangani karyawan saat penerimaan gaji. Rangkap pertama sebagai arsip disimpan manajer operasional, sedangkan yang kedua untuk karyawan bersangkutan.

Debet note dan slip gaji diserahkan manajer operasional pada direktur meminta persetujuan. Setelah disetujui, debet note diberikan kembali ke keuangan untuk diarsipkan. Bagian keuangan mengeluarkan dana diserahkan kepada manajer operasional untuk membayar gaji secara tunai beserta slip gaji. Karyawan menerima serta menandatangani slip gaji, dan menyerahkaan kembali slip tersebut kepada manajer operasional agar diarsipkan. 


\subsection{Analisis Kebutuhan Sistem}

Analisa kebutuhan sistem informasi penggajian karyawan dirancang sesuai dengan permasalahan dalam perusahaan dengan tujuan menciptakan pengolahan data penggajian yang lebih aktual dan mudah digunakan. Sistem informasi penggajian yang baru diharapkan dapat membantu dalam proses penggajian dari awal hingga pembuatan slip gaji. User Admin sebagai penggguna program mempunyai hak akses berupa (a) Admin dapat melakukan login; (b) Admin dapat mengakses menu dashboard; (c) Admin dapat mengelola data jabatan; (d) Admin dapat mengelola data karyawan; (e) Admin dapat mengakses data gaji dan mencetak slip gaji; (f) Admin dapat melakukan logout.

\subsection{Desain Sistem}

Desain sistem menggunakan UML karena pemodelan yang mudah dipahami dan mudah digunakan. Gambar 1 merupakan use case diagram sistem informasi pembayaran gaji. Use case diagram ini menggambarkan hubungan antara sistem dengan actor.

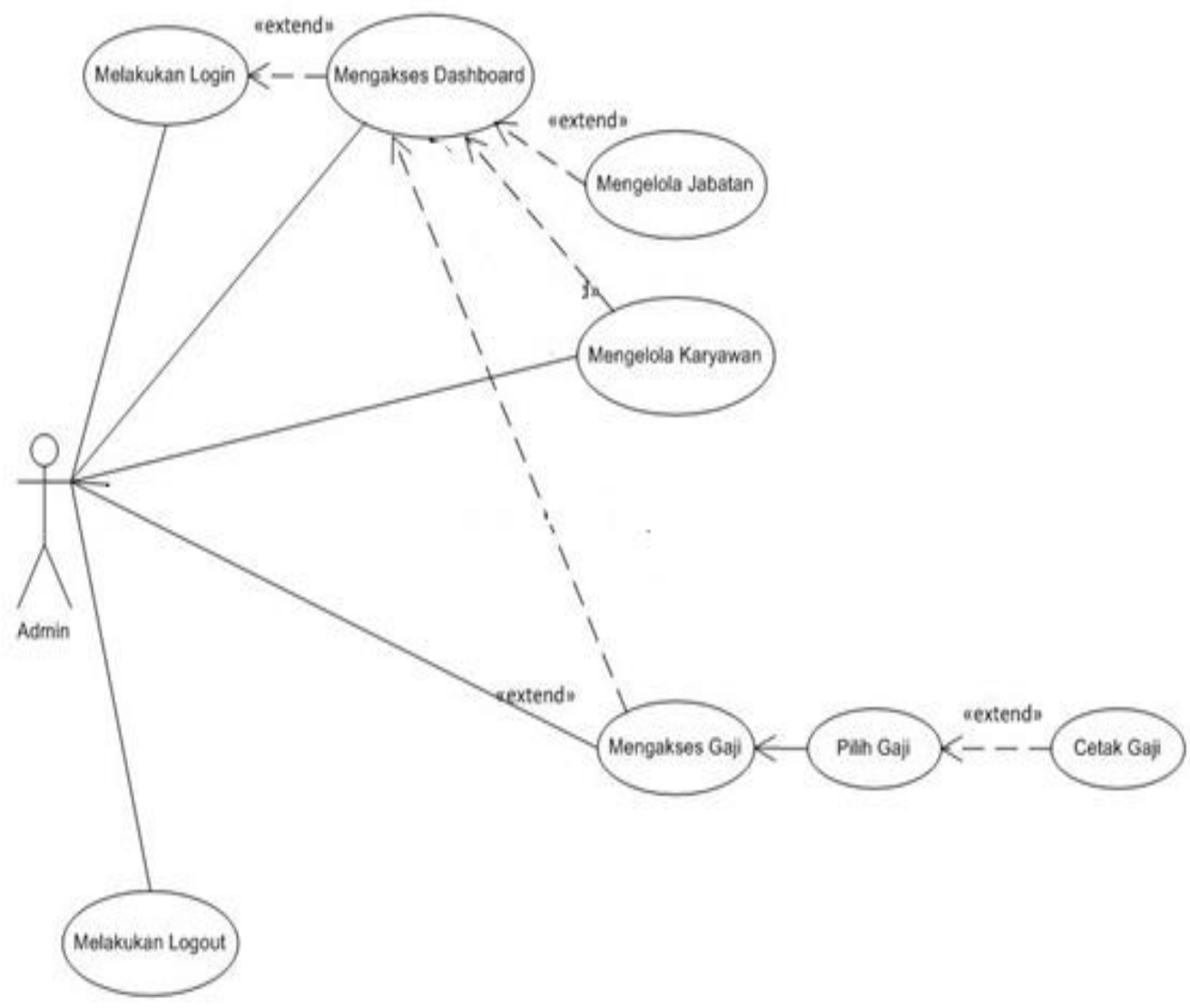

Sumber :Hasil Penelitian (2021)

Gambar 1. Use Case Diagram Sistem Informasi Penggajian

Desain sistem selanjutnya pada gambar 2 sequence diagram sistem informasi pembayaran gaji, yang menggambarkan bagaimana objek-objek saling berinteraksi melalui pesan yang ditukar dalam urutan waktu. 


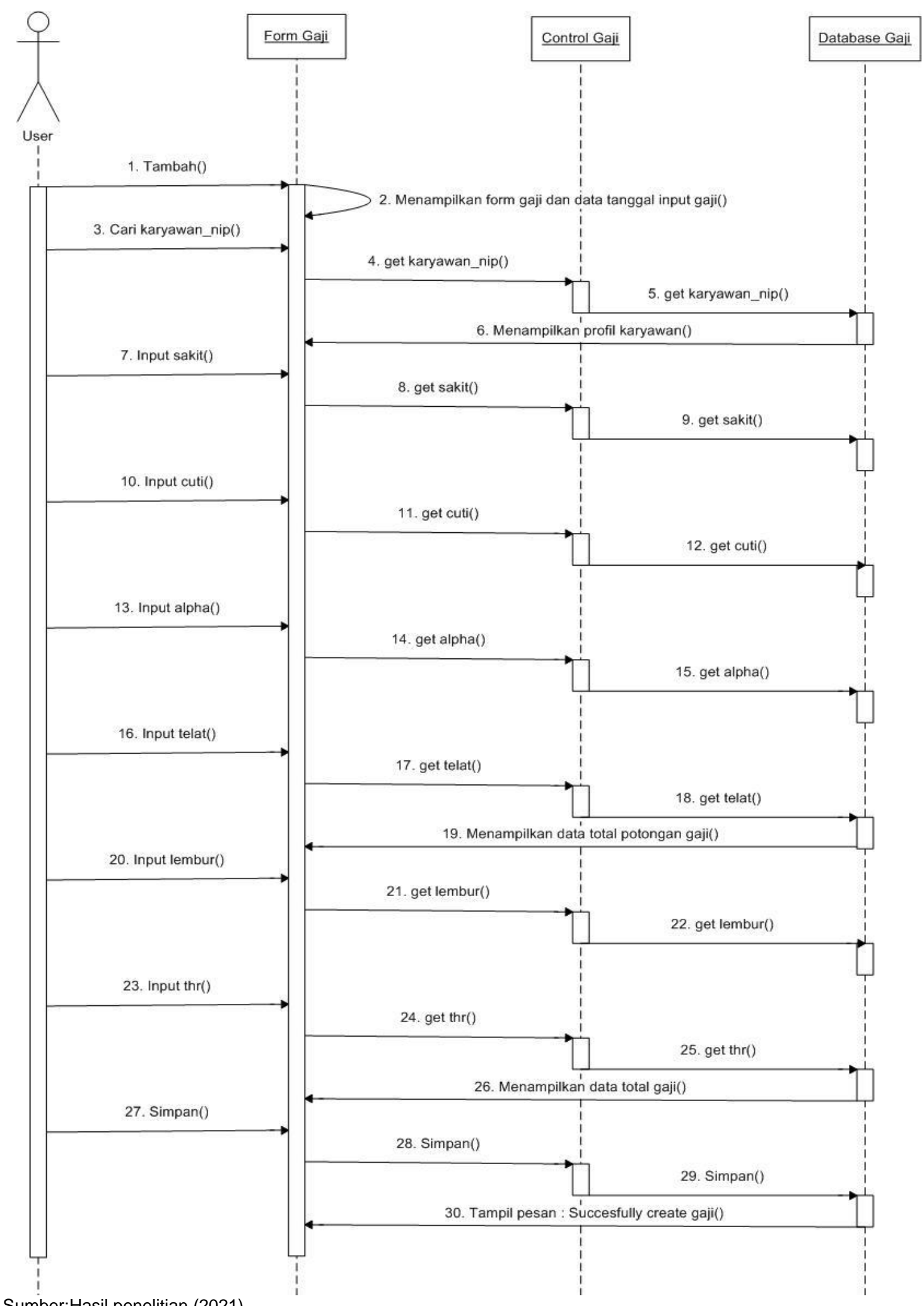

Sumber:Hasil penelitian (2021)

Gambar 2. Sequence Diagram Sistem Informasi Penggajian

Model data dengan diagram yang menghubungkan antara entitas satu dengan entitas lainnya dapat digambarkan melalui Entity Relation Diagram (ERD). 
Pada gambar $3 E R D$ sistem penggajian karyawan terdiri dari empat tabel yaitu tabel user, tabel karyawan, tabel jabatan dan tabel gaji.

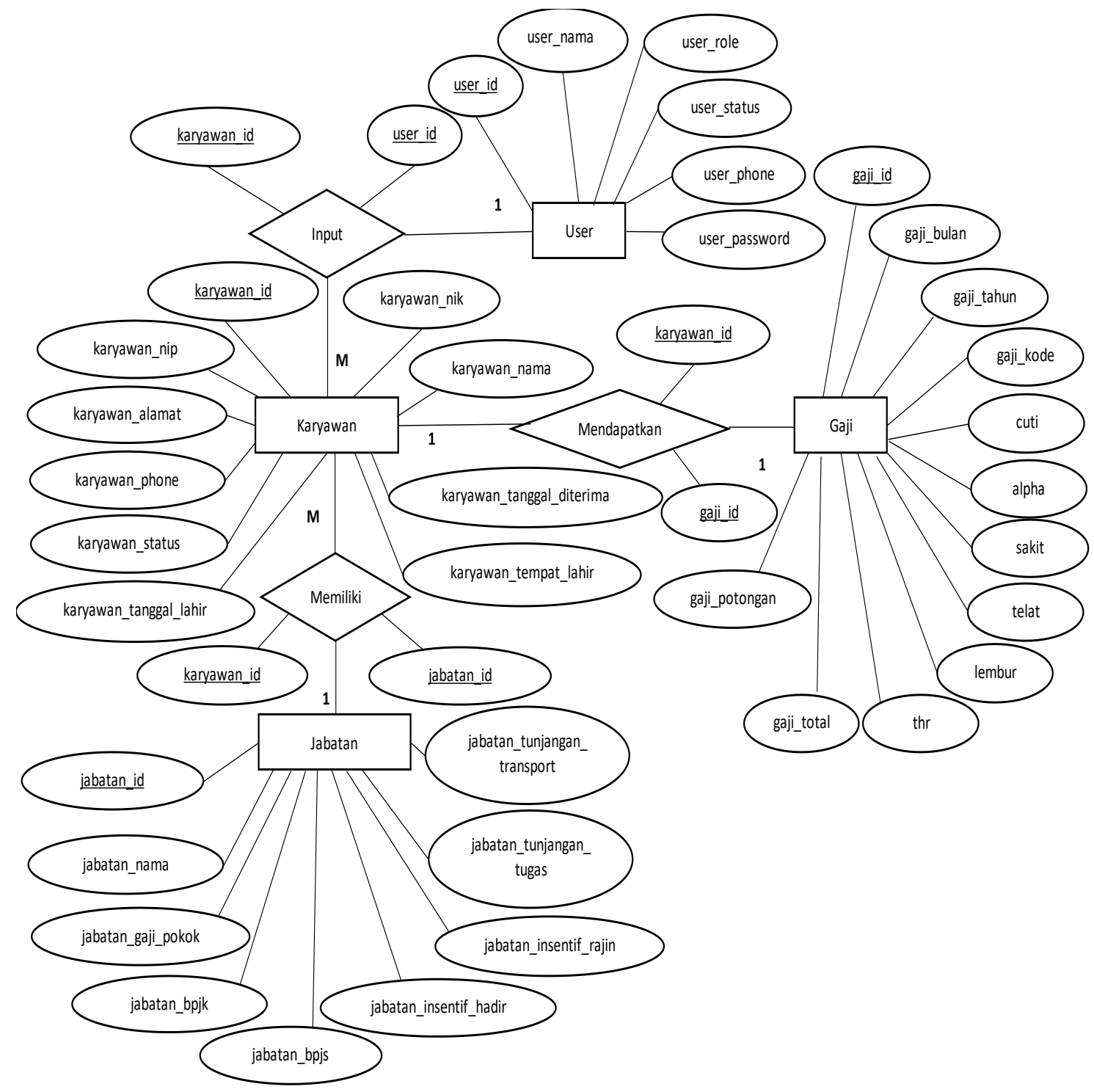

Sumber :Hasil Penelitian(2021)

Gambar 3. Entity Relation Diagram

\subsection{Implementasi User Interface}

User interface hasil dari peneliti membuat kode program yang diterjemahkan dalam perangkat lunak Java Netbeans IDE 8.0.2. User interface merupakan bentuk tampilan grafis yang berhubungan langsung dengan pengguna (user) berupa tampilan website sistem informasi penggajian karyawan pada PT Malka Makarya Selaras Jakarta.

Gambar 4 merupakan Halaman Login sebagai halaman awal dari website. Admin harus login terlebih dahulu dengan mengisi username dan password yang sudah terdaftar, jika username dan password valid akan berhasil masuk pada halaman dashboard sebagai menu utama tetapi jika username dan password tidak valid maka akan tampil messagebox sebagai tanda kesalahan login, sehingga harus login ulang. 


\section{PT. MALKA MAKARYA SELARAS}

\begin{tabular}{|c|}
\hline SIGN IN \\
\hline Username \\
\hline Password \\
\hline Sign In \\
\hline
\end{tabular}

Sumber : Hasil Penelitian (2021)

Gambar 4. Tampilan Halaman Login

Pada gambar 5 adalah tampilan halaman master data jabatan. Pada halaman ini admin dapat mengelola data jabatan yaitu melakukan pencarian data, menambah, mengedit atau menghapus data jabatan. Tampilan halaman master data jabatan juga mewakili tampilan halaman master data karyawan.

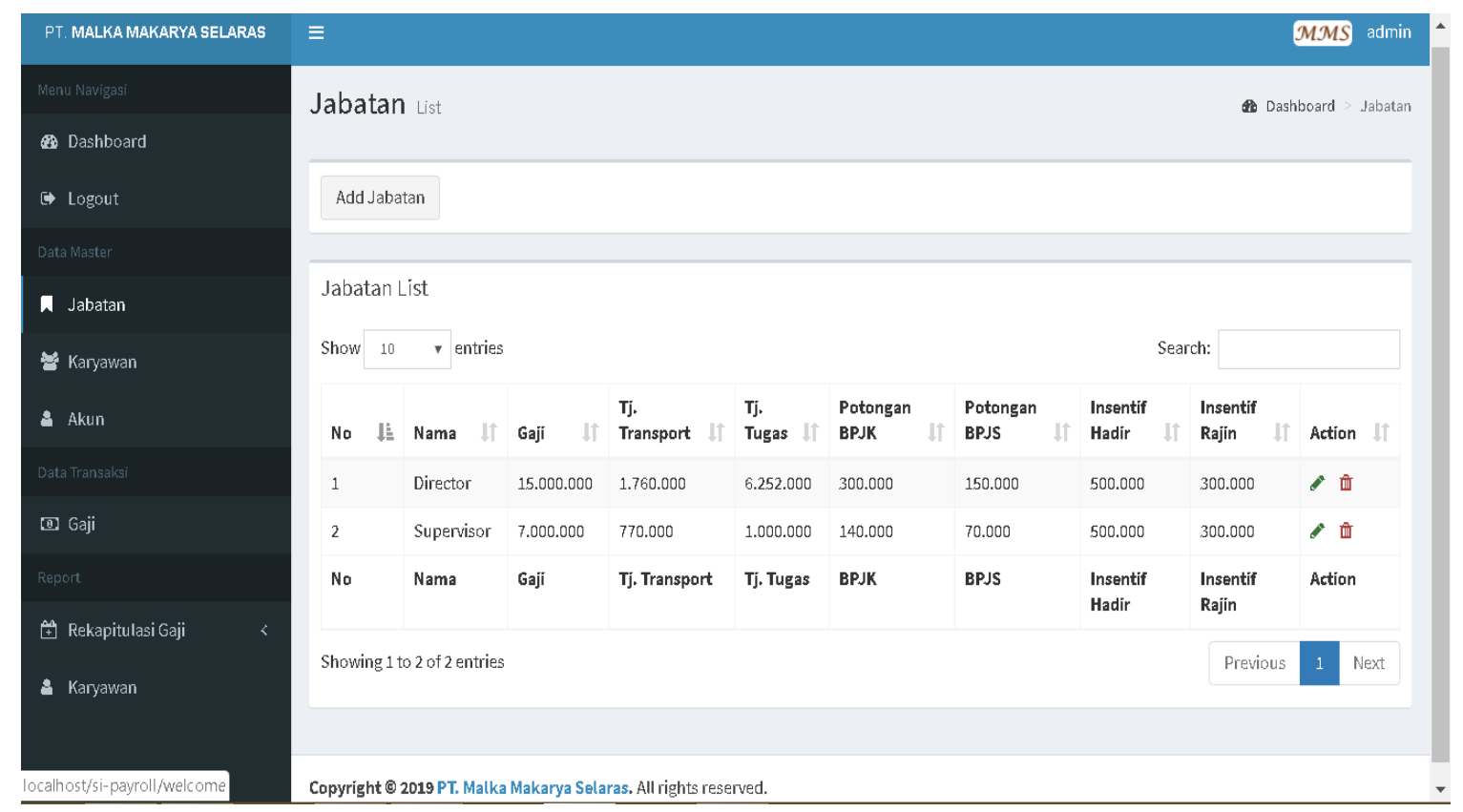

Sumber : Hasil Penelitian (2021)

Gambar 5. Tampilan Halaman Master Data Jabatan 
Pada gambar 6 halaman input data transaksi gaji, admin dapat menambah data transaksi gaji dengan mengisi NIP maka data gaji pokok, tunjangan, insentif dan potongan BPJS serta BPJSTK karyawan akan muncul. Kemudian user mengisi data sakit, cuti, alpha, telat, lembur dan THR maka akan muncul total potongan dan total gaji karyawan lalu klik simpan maka data transaksi gaji akan tersimpan dan secara otomatis slip gaji bisa dicetak.

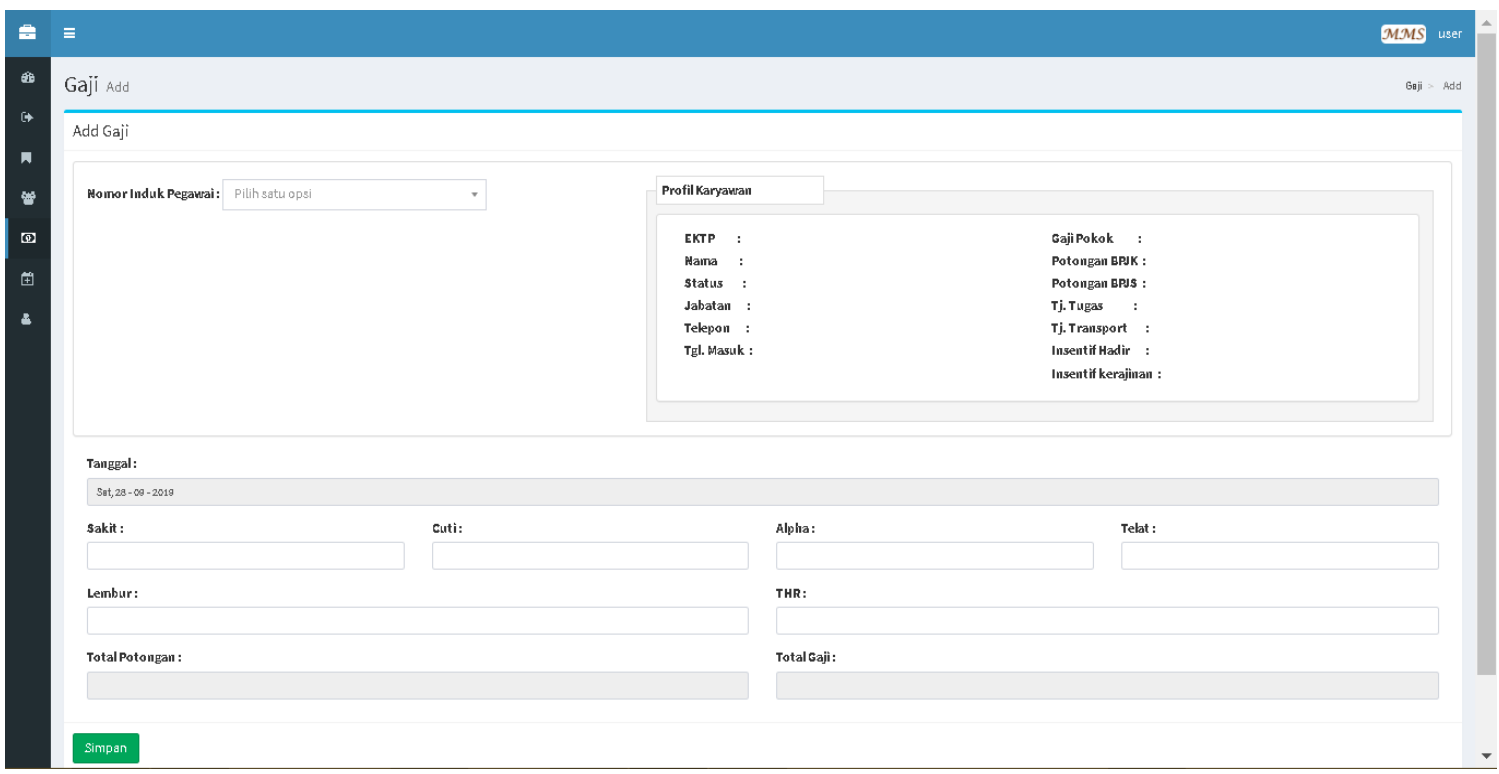

Sumber : Hasil Penelitian (2021)

Gambar 6. Tampilan Halaman Transaksi Penggajian

Selanjutnya pada gambar 7, Admin dapat melakukan pencarian data gaji dengan filter rekapitulasi gaji sesuai periode tertentu.

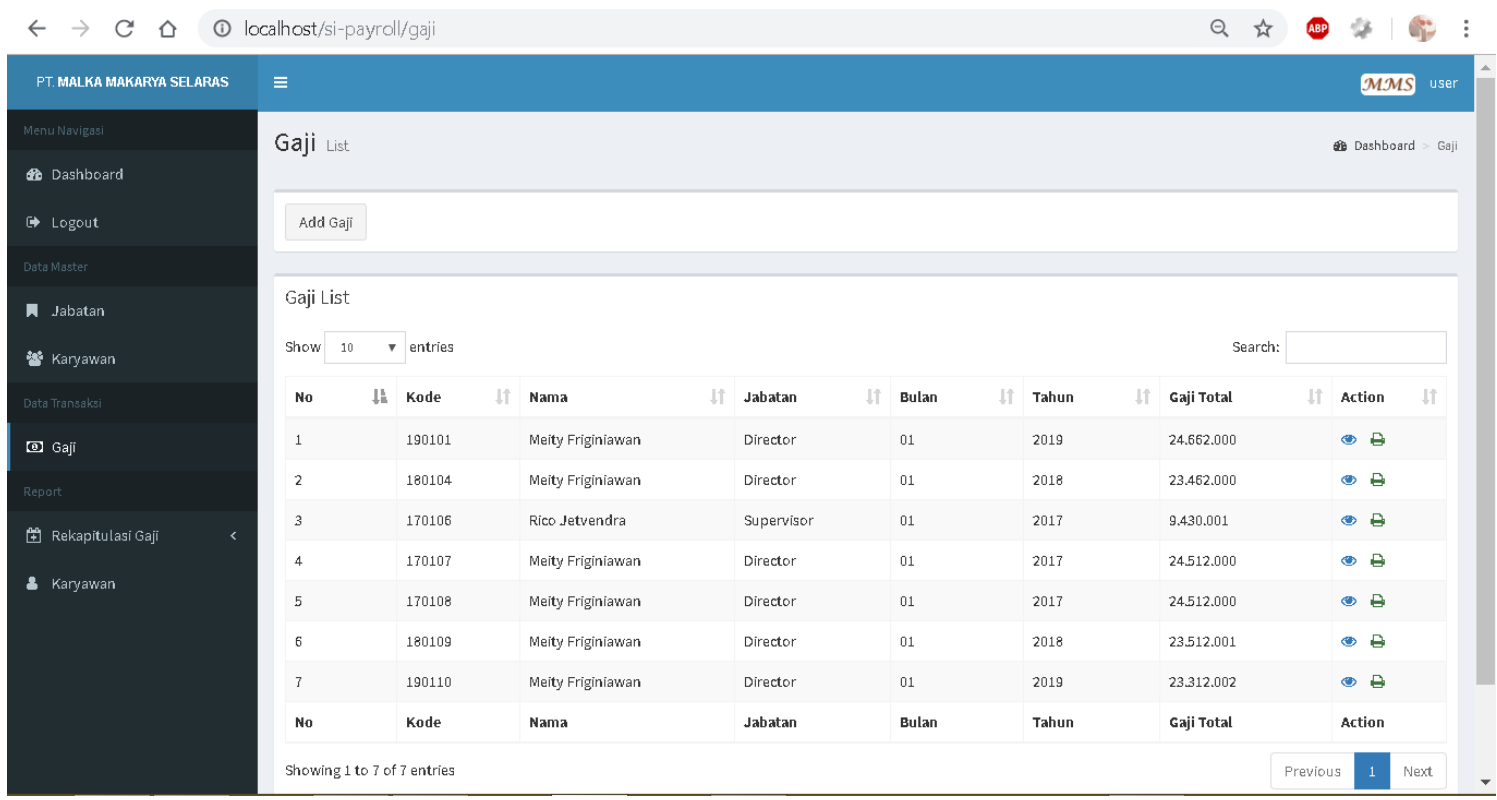

Sumber : Hasil Penelitian (2021)

Gambar 7. Tampilan Halaman Transaksi Penggajian 


\subsection{Pengujian Blackbox Testing}

Peneliti melakukan pengujian perangkat lunak secara keseluruhan. Dimulai saat melakukan login ke halaman website, melakukan input data karyawan, jabatan dan melakukan transaksi gaji agar sesuai dengan data masukkan yang ada. Pada Tabel 1 Pengujian Blackbox Testing oleh admin pada halaman transaksi gaji.

Tabel 1. Pengujian Blackbox Testing Halaman Transaksi Gaji

\begin{tabular}{|c|c|c|c|c|}
\hline $\begin{array}{l}\text { Skenario } \\
\text { Pengujian }\end{array}$ & Test Case & $\begin{array}{l}\text { Hasil Yang } \\
\text { diharapkan }\end{array}$ & Hasil Pengujian & Kesimpulan \\
\hline $\begin{array}{l}\text { Mengisi NIP tetapi } \\
\text { sakit, cuti, alpha, } \\
\text { telat, lembur dan } \\
\text { THR tidak diisi } \\
\text { atau kosong } \\
\text { kemudian klik } \\
\text { simpan. }\end{array}$ & $\begin{array}{l}\text { NIP : (ada) } \\
\text { Sakit : (kosong) } \\
\text { Cuti : (kosong) } \\
\text { Alpha : (kosong) } \\
\text { Telat : (kosong) } \\
\text { Lembur : (kosong) } \\
\text { THR : (kosong) }\end{array}$ & $\begin{array}{l}\text { Sistem akan } \\
\text { menampilkan } \\
\text { "Harap isi bidang } \\
\text { ini!" }\end{array}$ & Sesuai harapan & Valid \\
\hline $\begin{array}{l}\text { Mengisi NIP lalu } \\
\text { sakit, cuti, alpha, } \\
\text { telat, lembur dan } \\
\text { THR diisi selain } \\
\text { angka kemudian } \\
\text { klik simpan. }\end{array}$ & $\begin{array}{l}\text { NIP : (ada) } \\
\text { Sakit : (ada) } \\
\text { Cuti : (ada) } \\
\text { Alpha : (ada) } \\
\text { Telat : (ada) } \\
\text { Lembur : (ada) } \\
\text { THR : (ada) }\end{array}$ & $\begin{array}{l}\text { Sistem akan } \\
\text { menampilkan } \\
\text { "Masukkan } \\
\text { nomor." }\end{array}$ & Sesuai harapan & Valid \\
\hline $\begin{array}{l}\text { Mengisi NIP (NIP } \\
\text { karyawan yang } \\
\text { sudah ada data } \\
\text { gajinya) lalu sakit, } \\
\text { cuti, alpha, telat, } \\
\text { lembur dan THR } \\
\text { kemudian klik } \\
\text { simpan. }\end{array}$ & $\begin{array}{l}\text { NIP : (ada) } \\
\text { Sakit : (ada) } \\
\text { Cuti : (ada) } \\
\text { Alpha : (ada) } \\
\text { Telat : (ada) } \\
\text { Lembur : (ada) } \\
\text { THR : (ada) }\end{array}$ & $\begin{array}{l}\text { Sistem akan } \\
\text { menampilkan } \\
\text { "Data Gaji } \\
\text { Karyawan Sudah } \\
\text { Diinput." }\end{array}$ & Sesuai harapan & Valid \\
\hline $\begin{array}{l}\text { Mengisi NIP, sakit, } \\
\text { cuti, alpha, telat, } \\
\text { lembur dan THR } \\
\text { kemudian klik } \\
\text { simpan. }\end{array}$ & $\begin{array}{l}\text { Sakit : (ada) } \\
\text { Cuti : (ada) } \\
\text { Alpha : (ada) } \\
\text { Telat : (ada) } \\
\text { Lembur : (ada) } \\
\text { THR : (ada) }\end{array}$ & $\begin{array}{l}\text { Sistem akan } \\
\text { menyimpan data } \\
\text { dan menampilkan } \\
\text { "Successfully } \\
\text { Create Gaji" }\end{array}$ & Sesuai harapan & Valid \\
\hline
\end{tabular}

\section{Kesimpulan}

Berdasarkan hasil penelitian dan pembahasan yang dilakukan pada sistem informasi penggajian karyawan pada PT Malka Makarya Selaras Jakarta, sistem yang sudah 
terkomputerisasi tersebut ditampilkan dalam halaman website internal perusahaan yang pengelolanya hanyalah petugas khusus penggajian. Hasil penelitian terdapat beberapa kesimpulan (a) Proses perhitungan gaji yang sebelumnya masih manual dapat dilakukan pada sistem informasi penggajian karyawan sehingga menghasilkan informasi yang lebih cepat dan akurat; (b) Melalui sistem informasi penggajian dapat secara langsung mencetak slip gaji sebagai bukti resmi antara perusahaan dengan karyawan; (c) Adanya sistem informasi penggajian sebagai tolak ukur kemajuan teknologi di PT Malka Makarya Selaras Jakarta sehingga mempermudah kinerja perusahaan dalam pengambilan keputusan.

\section{Daftar Pustaka}

Ariyati, I. (2018). Pengembangan Sistem Informasi Perpustakaan Sekolah. PILAR Nusa Mandiri, 14(1), 55-60.

Faizah, S., Afif, I. S. F. Al, \& Ariyati, I. (2020). Sistem Informasi Pendapatan Jasa Pada Sekolah $\begin{array}{llllll}\text { Mengemudi Ar'rahman. BINA INSANI ICT JOURNAL, } & \text { 7(2), } & 125 .\end{array}$ https://doi.org/10.51211/biict.v7i2.1405

Hardi, N., \& Leidiyana, H. (2020). Sistem Informasi Program Persediaan Barang. Journal of Students' Research in Computer Science (JSRCS), 1(2), 89-96.

Hidayatun, N. (2016). Problem Solving Sistem Penggajian Karyawan. Indonesian Journal on Computer and Information Technology, 1(2), 1-9.

Istiana, D., \& Ariyati, I. (2017). Disetujui: 26 Oktober 2017 Cara sitasi: Istiana D, Ariyati I. 2017. Sistem Informasi Akuntansi Perusahaan Dagang Menggunakan Zahir Accounting Versi 5.1. Information Management For Educators and Professionals. Information Management for Educators and Professionals, 2(1), 11-20.

Mania, M., Purnama, B. E., \& Sukadi. (2016). Sistem Informasi Penggajian Karyawan Mitra Karya Prima Di Pembangkit Listrik Tenaga Uap 1 Pacitan. IJSE - Indonesian Journal on Software Engineering, 2(1), 39-43.

Misriati, T. (2015). Rancang Bangun Sistem Pelayanan Jasa Pengecatan Suku Cadang Kendaraan Bermotor. Jurnal Teknik Komputer, 1(1), 123-133. http://ejournal.bsi.ac.id/ejurnal/index.php/jtk/article/view/243

Muslihudin, M., \& Oktafianto. (2016). Analisis dan Perancangan Sistem Informasi Menggunakan Model Terstruktur dan UML. CV. Andi Offset.

Rahaningsih, N., Iriano, P., \& Ulfanisa, N. (2019). Rancang Bangun Sistem Informasi Akuntansi Penggajian Karyawan Di PT. Saiya Indonesia. Jurnal ICT : Information Communication \& Technology (JICT), 1-5.

Siswanto, E., \& Alfiandanu, W. A. (2015). Sistem Informasi Pengolahan Data Gaji dan Perhitungan PPH Pasal 21 Pada CV Sinar Jasa Teknik Ngaliyan Semarang. Jurnal IImiah Komputer Akuntansi STEKOM Semarang, 8, 69-75.

Sukamto, R. A., \& Shalahuddin, M. (2015). Rekayasa Perangkat Lunak Struktur dan Berorientasi Objek. Informatika Bandung. 